\title{
Flora das cangas da Serra dos Carajás, Pará, Brasil: Vitaceae
}

\author{
Flora of the cangas of the Serra dos Carajás, Pará, Brazil: Vitaceae
}

\author{
Julio Antonio Lombardi ${ }^{1}$
}

\begin{abstract}
Resumo
São apresentadas as espécies de Vitaceae registradas para as áreas de canga da Serra dos Carajás, estado do Pará, incluindo descrições morfológicas, ilustrações, distribuição e comentários. Foram encontradas quatro espécies de Cissus para a região: C. apendiculata, espécie restrita aos estados do Maranhão, Pará e Tocantins, e as espécies amplamente distribuídas C. erosa, C. tinctoria e C. verticillata subsp. verticillata.

Palavras-chave: Cissus, FLONA Carajás, flora, taxonomia.

Abstract

The Vitaceae species registered for the areas of canga at Serra dos Carajás, Pará State. Morphological descriptions, illustrations, distribution, and comments are given. Four species of Cissus were found in the region: $C$. apendiculata, restricted to the states of Maranhão, Pará, and Tocantins, and the widely distributed C. erosa, C. tinctoria, and C. verticillata subsp. verticillata.
\end{abstract}

Key words: Cissus, FLONA Carajás, flora, taxonomy.

\section{Vitaceae}

Vitaceae L. inclui 14 a 15 gêneros quase exclusivamente de lianas com folhas simples, trifolioladas, digitadas ou pinadas e gavinhas e inflorescências opostas às folhas. Na América do Sul ocorrem apenas Vitis L. com uma espécie (V. tiliifolia Humb. \& Bonpl. ex Roem. \& Schult., na Colômbia, Venezuela e Equador), Clematicissus Planch. com quatro espécies (Lombardi 2015) e Cissus L. com 64 espécies (Lombardi 2000, 2007), em ampla variedade de habitats. No Brasil ocorrem 48 espécies descritas de Cissus, 15 delas endêmicas (BFG 2015). Embora o gênero Cissus tenha resultado como polifilético na região Neotropical em análises anteriores (Liu et al. 2013; Rodrigues et al. 2014), a segregação de Clematicissus (Lombardi 2015), aparentemente resolveu esse problema se Cissus trianae Planch. deve permanecer no gênero (Zhang et al. 2015). Na Serra dos Carajás foram registradas cinco espécies de Cissus, quatro delas ocorrentes em áreas de canga e $C$. araguainensis Lombardi, registrada em região de mata de transição fechada.

\section{Cissus L.}

O gênero Cissus é caracterizado pelas flores tetrâmeras com disco nectarífero desenvolvido (Lombardi 2000). Todas são lianas escandentes por meio de gavinhas, embora algumas espécies campestres possam ser classificadas como subarbustos. Suas folhas são simples ou compostas trifolioladas, digitadas ou pinadas, sempre de margem denticulada; as inflorescências são cimeiras compostas umbeliformes, as brácteas são escamiformes, as flores amarelo-esverdeadas ou vermelhas tem cálice reduzido e inconspícuo, geralmente truncado, pétalas valvares e estames opostos a estas, estames de ca. $1 \mathrm{~mm}$, disco nectarífero envolvendo o ovário; ovário súpero bicarpelar e bilocular com dois óvulos por lóculo, estilete central de $0,5-1 \mathrm{~mm}$, estigma pontual; os frutos são bagas, geralmente púrpuras, com uma ou duas sementes. Tradicionalmente inclui cerca de 350 espécies amplamente distribuídas nas regiões tropicais da África, Américas, sul da Ásia, Austrália e Papuásia (Lombardi 2000).

\footnotetext{
${ }^{1}$ Universidade Estadual Paulista - UNESP, Inst. Biociências, Depto. Botânica, , Av. 24 A, 1515, Bela Vista, 13506-900, Rio Claro, SP, Brasil.

${ }^{2}$ Autor para correspondência: cissus@rc.unesp.br
} 


\section{Chave de identificação das espécies de Cissus das cangas da Serra dos Carajás}

1. Folhas simples.

2. Folhas enegrecidas quando secas, triangulares ou cordiformes, tricomas não ramificados e malpighiáceos pequenos e inconspícuos presentes. 1.3. Cissus tinctoria

2'. Folhas não enegrecidas quando secas, triangulares ou elípticas, somente tricomas não ramificados presente 1.4. Cissus verticillata subsp. verticillata

1'. Folhas compostas trifolioladas.

3. Flores amarelo-esverdeadas, cálice com projeções filiformes na base, tricomas glandulares presentes, não ramificados, frutos híspidos, alados 1.1. Cissus apendiculata

3'. Flores vermelhas, cálice desprovido de projeções filiformes na base, tricomas glandulares ausentes, ramificados presentes, frutos glabros, lisos. 1.2. Cissus erosa

1.1 Cissus apendiculata Lombardi, Novon 6: 197, f. 2 A-F. 1996.

Fig. 1a

Lianas, tricomas não ramificados, glandulares e não glandulares; ramos avermelhados, subcilíndricos, híspidos. Folhas trifolioladas, híspidas; pecíolos 1,8-5,2 cm compr.; estípulas falcadas; peciólulos 0-4 mm; lâminas dos folíolos $1,5-10,5 \times 0,8-4,2 \mathrm{~cm}$, rômbicas, subelípticas ou fusiformes, ápice agudo, acuminado ou caudado, margem denticulada, base atenuada ou cuneada, às vezes levemente dicolores e avermelhadas, papiráceas. Inflorescências 2-5,3 $\times 2,1-4,1 \mathrm{~cm}$, híspidas; pedúnculos $1-2,7 \mathrm{~cm}$ compr., verdes; pedicelos $3-5 \mathrm{~mm}$, esverdeados. Cálice $0,5-1 \times 1-1,5 \mathrm{~mm}$, verde-amarelado, piloso, base lateralmente apendiculada com 1-3 lobos filiformes de ca. $2 \mathrm{~mm}$. Corola em botão 1-1,5 × $1 \mathrm{~mm}$; pétalas verde-amareladas, pilosas no ápice. Estames verdes. Disco amarelo. Estilete e estigma verdes. Baga ca. 1,5 $\times 1 \mathrm{~cm}$, elipsóide, híspida, alada; semente ca. $8 \times 5 \mathrm{~mm}$, subturbinada, achatada.

Material selecionado: Canaã dos Carajás, Serra Sul, Corpos A, B e C, 6020'47'S 50²4'29'W, 8.XII.2007, fl., N.F.O. Mota 1125 (BHCB, HRCB, MG), Serra do Tarzan, 619'50"S 50¹0'15"W, 13.III.2009, fl. e fr., V.T. Giorni 113 (BHCB); Parauapebas [Marabá], Serra Norte, N1, 15.XI.1989, fl., J.P. Silva 338 (MG); Serra Norte, N4, 20.III.1984, fr., A. S. L. Silva et al. 1940 (MG, MO, NY).

Cissus apendiculata é a única das espécies neotropicais até agora conhecidas que apresenta cálice com apêndices filiformes na base e frutos pilosos e alados, sendo esta última condição nem sempre detectável em exemplares herborizados com frutos maduros. Sua pilosidade glandular dá à planta uma textura viscosa e perceptível odor quando manipulada.

Restrita às regiões nordeste e norte do Brasil, onde ocorre nos estados do Maranhão (Monção), Tocantins (Araguaína), e Pará (Monte Alegre,
Parauapebas e Canaã dos Carajás). Serra dos Carajás. Serra Norte: N1, N4; Serra Sul: Corpos A, B e C, Serra do Tarzan. Ocorre em bordas de matas e beiras de lagoas na canga com mata baixa.

1.2. Cissus erosa Richard, Actes Soc. Hist. Nat. Paris 1: 106. $1792 . \quad$ Fig. 1b

Lianas, tricomas ramificados e não ramificados, não glandulares; ramos avermelhados, angulados, alados a subcilíndricos, híspidos ou subtomentosos, glabrescentes. Folhas trifolioladas; pecíolos $0,7-2,5 \mathrm{~cm}$, híspidos ou subtomentosos, glabrescentes; estípulas oblongas, gibosas na base, glabras; peciólulos $2-5 \mathrm{~mm}$, híspidos, glabrescentes; lâminas dos folíolos 4,3-10,5 × 1,2-5,2 cm elípticas ou oblongas, ápice agudo, base atenuada ou cuneada, tomentosas ou híspidas, glabrescentes, papiráceas. Inflorescências 3,8$17,8 \times 3,1-8,4 \mathrm{~cm}$; pedúnculos 2,4-11 cm compr., vermelhos, tomentosos ou seríceos, glabrescentes; pedicelos 1,5-3 mm, vermelhos, seríceos, glabrescentes. Cálice 0,5-1 × 1-2 mm, vermelho, seríceo na base, base arredondada. Corola em botão 1-2 × 1-2 mm; pétalas vermelhas externamente e internamente laranja, glabras. Estames amarelos, conectivo vermelho. Disco alaranjado-avermelhado, vermelho no ápice. Estilete vermelho, estigma verde a rosado. Baga ca. $6 \mathrm{~mm}$, esférica, púrpura, glabra; semente ca. 5 $\times 4 \mathrm{~mm}$, subturbinada, arredondada.

Material selecionado: Canaã dos Carajás, Serra Sul, Corpo B, 6'22'53'S 50²3'40,14'W, 30.V.2010, infectado, L.L. Giacomin et al. 1163 (BHCB); Parauapebas [Marabá], Bocaina, 6 ${ }^{\circ} 18^{\prime} 12^{\prime \prime} \mathrm{S} 49^{\circ} 53^{\prime}$ '55'W, 15.XII.2010, fl., N.F.O. Mota 1882 (BHCB); Serra Norte, N4, 10.I.2010, fl., L.C.B. Lobato 3776 (MG); N5, 29.I.1985, fl., O.C. Nascimento \& R.P. Bahia 1053 (MG).

Cissus erosa apresenta ampla variação morfológica, particularmente notável nos cerrados brasileiros, onde indivíduos de porte subarbustivo 

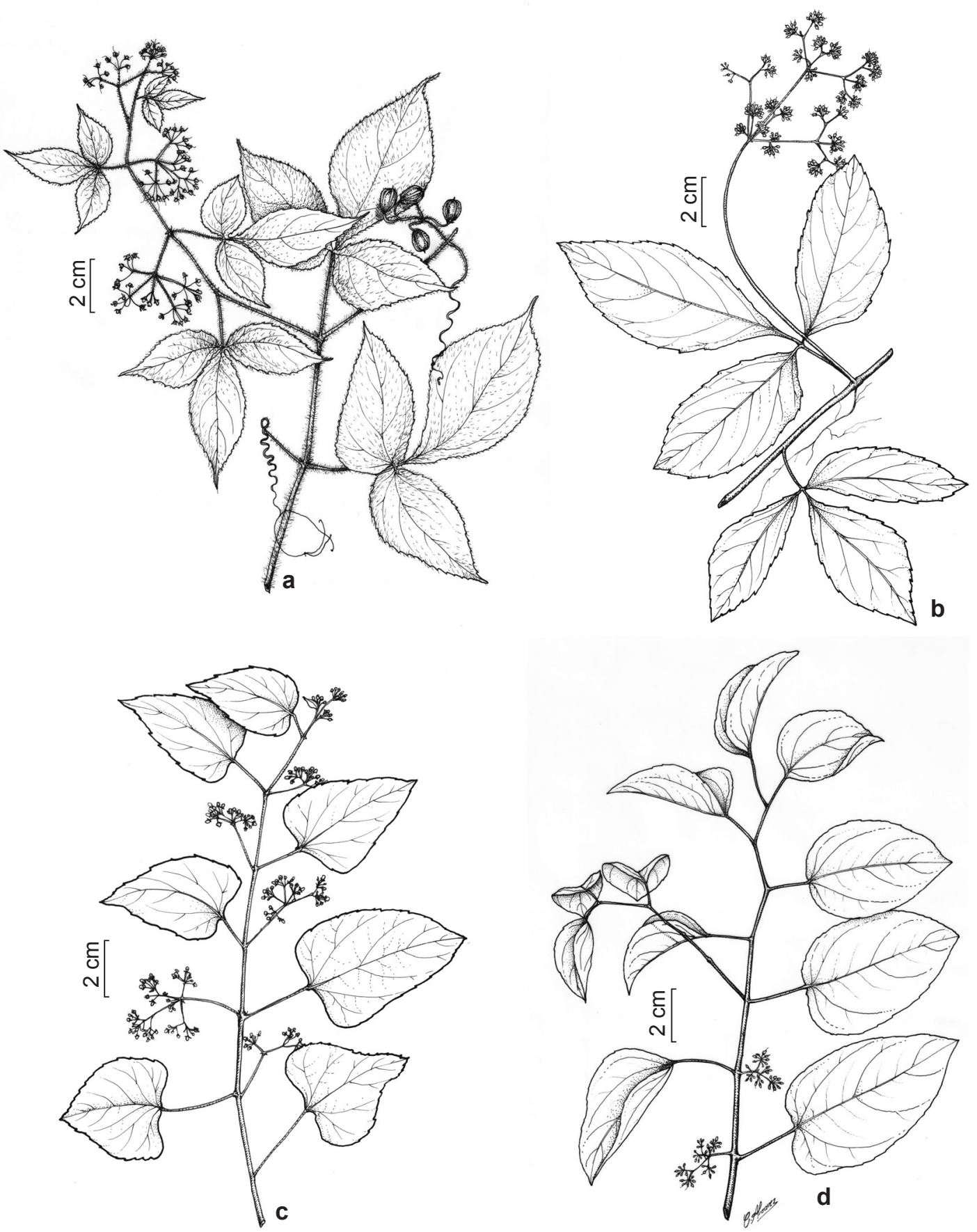

Figura 1 - a. Cissus apendiculata - hábito; b. Cissus erosa - hábito; c. Cissus tinctoria - hábito; d. Cissus verticillata subsp. verticillata - hábito (a. N.F.O. Mota 1125; b. N.F.O. Mota 1882; c. C.R. Sperling 5691; d. C.R. Sperling 5677). Figure 1 - a. Cissus apendiculata - habit; b. Cissus erosa - habit; c. Cissus tinctoria - habit; d. Cissus verticillata subsp. verticillata habit (a. N.F.O. Mota 1125; b. N.F.O. Mota 1882; c. C.R. Sperling 5691; d. C.R. Sperling 5677). 
representam, ocasionalmente, exceções à regra de todas as espécies de Vitaceae serem lianas. As folhas de $C$. erosa são também extremamente variadas nesse bioma, sendo observados indivíduos de folhas trifolioladas a até folhas simples trilobadas, alguns com pecíolo extremamente curto. Estas variações, no entanto, não foram observadas nas amostras estudadas para a Serra dos Carajás. Alguns espécimes foram coletados na região portando galhas tipo vassoura-de-bruxa, causadas pela infestação pelo fungo Mycosyrinx cissi (Poir.) Beck (Basidiomycota, Ustilaginales), como em L.L. Giacomin et al. 1163 (BHCB).

Amplamente distribuída na região neotropical, desde o México até o Paraguai. No Brasil ocorre em todos os Estados, exceto Santa Catarina e Rio Grande do Sul. Serra dos Carajás: Bocaina; Serra Norte: N1, N4, N5; Serra Sul: Corpo B. Ocorre em margens de lagoas, buritiranais, campos rupestres e em matas baixas.

1.3. Cissus tinctoria Mart. in Spix \& Martius, Reise Bras. 1: 368. 1823.

Fig. 1c

Lianas, secando enegrecidas, tricomas ramificados e não ramificados, não glandulares ; ramos subcilíndricos, pubérulos, glabrescentes. Folhas simples; pecíolos 1,1-6,3 cm, pubérulos; estípulas triangulares, base auriculada; lâminas 4,1-10,5 × 4-8 cm, triangulares ou cordiformes, ápice acuminado, margem denticulada, base cordada, subcordada ou truncada, lâminas glabras ou pubérulas ao longo das nervuras na face adaxial, pubérulas na face abaxial, membranáceas ou papiráceas, secas comumente com manchas alvacentas. Inflorescências 3,8-7,5 × 2,8-3,5 cm; pedúnculos 1,6-3,9 cm compr., verdes, pubérulos e seríceos nas extremidades; pedicelos 2-3 mm compr., esverdeados, glabros. Cálice 1-2 × 1,5-3 $\mathrm{mm}$, verde-amarelado, glabro, base arredondada. Corola em botão $1,5-2 \times 1-2,5 \mathrm{~mm}$; pétalas verde-amareladas, glabras. Estames com filetes esverdeados, anteras e conectivo amarelos. Disco amarelo. Estilete verde, estigma verde. Baga ca. 1 $\mathrm{cm}$, esférica, púrpura, glabra; semente ca. 6,5 × 4 mm, subturbinada, arredondada.

Material selecionado: Parauapebas [Marabá], Serra Norte, N4, 20.III.1984, fl., A.S.L. Silva et al. 1928 (MG, NY); N5, 15.V.1982, fr., C.R. Sperling et al. 5691 (MG, NY).

Cissus tinctoria distingue-se, quando seca, das outras espécies analisadas por ser caracteristicamente enegrecida, de consistência frágil, pelas folhas predominantemente cordiformes, e também pela presença nas inflorescências, e às vezes esparsos em outras partes, de pequenos tricomas malpighiáceos adpressos. Apresenta variação morfológica entre as populações da região Sudeste do Brasil e aquelas na região Norte, as primeiras apresentando folhas levemente buladas que, nos ramos vegetativos são comumente oblongas e às vezes 3-5-lobadas, e nos reprodutivos oblongas ou elípticas, enquanto as últimas têm folhas não dimórficas entre os ramos vegetativos e reprodutivos, comumente cordiformes, não lobadas e não buladas.

Amplamente distribuída no Brasil nas regiões Nordeste, Sudeste, Centro-Oeste (Mato Grosso) e Norte (Pará e Rondônia), também na Bolívia. Serra dos Carajás. Serra Norte: N4, N5. Ocorre em margens de lagoas, campos rupestres e bordas de mata.

1.4. Cissus verticillata (L.) Nicolson \& C.E.Jarvis subsp. verticillata, Taxon 33: 727. 1984.

Fig. 1d

Lianas; tricomas não ramificados e não glandulares; ramos subcilíndricos, pubérulos, glabrescentes. Folhas simples, pecíolos 1-4,1 $\mathrm{cm}$, pubérulos; estípulas falcadas, glabras, base auriculada; lâminas 5,2-8,4 × 3-6,3 cm, ovais, triangulares ou elípticas, ápice agudo a acuminado, base truncada a subcordada, lâminas pubérulas ao longo das nervuras na face abaxial, esparso pubérulas na face adaxial ao longo da nervura principal, papiráceas. Inflorescências 2-2,5 $\times$ 1,8-2 cm; pedúnculos 0,7-0,9 cm compr., verdes, pubérulos; pedicelos ca. $2 \mathrm{~mm}$, verdes, glabros. Cálice $0,5 \times 1 \mathrm{~mm}$, verde-amarelado, glabro, base arredondada. Corola em botão $1,5 \times 1 \mathrm{~mm}$; pétalas verde-amareladas, glabras. Estames com filetes verde-amarelados, anteras amarelas, conectivo esverdeado. Disco esverdeado. Estilete e estigma verdes. Baga ca. $1 \mathrm{~cm}$, esférica, púrpura, glabra; semente ca. $5 \times 3 \mathrm{~mm}$, subturbinada, arredondada. Material examinado: Canaã dos Carajás, Parauapebas [Marabá], N5, 15.V.1982, fl., C.R. Sperling et al. 5677 (MG).

Cissus verticillata é a mais amplamente distribuída espécie de Vitaceae na região neotropical, apresentando larga variação morfológica quanto ao formato das folhas, com excepcionais espécimes trifoliolados ou de folhas lobadas no estado de São Paulo, e pilosidade, incluindo desde espécimes com indumento viloso até glabros. Na Serra dos Carajás apenas um espécime foi examinado, dados de frutos e sementes são baseados em coletas de outras localidades (Lombardi 2000). 
Amplamente distribuída no Neotrópico, ocorrendo no sul da Flórida, nos E.U.A., México, toda América Central, Caribe, e toda a América do Sul, exceto Chile e centro-sul da Argentina. No Brasil: em todos os Estados. Serra dos Carajás. Serra Norte: N5. Ocorre em vegetação secundária sobre formação savânica.

\section{Agradecimentos}

Agradeço ao projeto objeto do convênio MPEG/ITV/FADESP (01205.000250/2014-10) e ao projeto aprovado pelo CNPq (processo 455505/20144), o financiamento. Aos organizadores do projeto da Flora Rupestre de Carajás, o convite para elaborar esta monografia; aos curadores dos herbários citados, o acesso aos espécimes estudados.

\section{Referências}

BFG. 2015. Growing knowledge: an overview of seed plant diversity in Brazil. Rodriguésia 66: 1085-1113.
Liu, X.-Q.; Ickert-Bond, S.M.; Chen, L.-Q. \& Wen, J. 2013. Molecular phylogeny of Cissus L. of Vitaceae (the grape family) and evolution of its pantropical intercontinental disjunctions. Molecular Phylogenetics and Evolution 66: 43-53.

Lombardi, J.A. 2000. Vitaceae - Gêneros Ampelocissus, Ampelopsis e Cissus. Flora Neotropica Monograph Vol. 80, pp. 1-250.

Lombardi, J.A. 2007. Systematics of Vitaceae in South America. Canadian Journal of Botany 85: 712-721.

Lombardi, J.A. 2015. New combinations for the South American Cissus striata clade (Vitaceae). Phytotaxa 227: 295-298.

Rodrigues, J.G.; Lombardi, J.A. \& Lovato, M.B. 2014. Phylogeny of Cissus (Vitaceae) focusing on South American species. Taxon 63: 287-298.

Zhang, N.; Wen, J. \& Zimmer, E.A. 2015. Congruent deep relationships in the grape family (Vitaceae) based on sequences of chloroplast genomes and mitochondrial genes via genome skimming. PLoS ONE 10: e0144701. DOI: 10.1371/journal. pone. 014470 .

\section{Lista de exsicatas}

Daly, D.C. 1776 (1.1, parátipo); Giacomin, L.L. 1163 (1.2); Giorni, V.T. 84 (1.2), 113 (1.1), 223 (1.2); Lobato, L.C.B. 3776 (1.2); Lobato, L.C.B. 2592 (1.1); Mota, N.F.O. 1125 (1.1), 1882, 1922 (1.2); Nascimento, O.C.\& Bahia, R.P. 931 (1.2); 961 (1.1, holótipo), 968 (1.3), 1053 (1.2); Secco, R. 162 (1.2); Silva, A.S.L. da 1797 (1.2), 1928 (1.3), 1940 (1.1, parátipo); Silva, J.P. 338 (1.1); Silva, L.C. BHCB 50783 (1.1); Silva, M.G. \& Bahia, R. 2950 (1.3); Sperling, C.R. 5629 (1.2), 5677 (1.4), 5691 (1.3); Viana, P.L. 4026 (1.2). 
